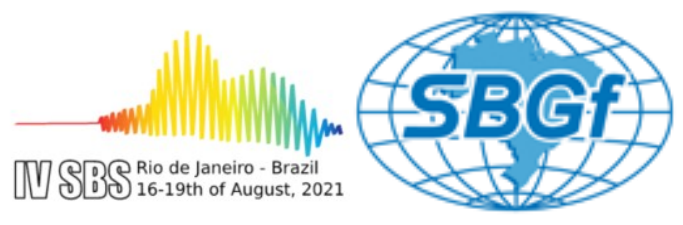

\title{
Analysis of infrasonic signals generated by an accidental explosion on July 3, 2020 at a fireworks factory in Turkey
}

Matheus Fernandes da Cruz ${ }^{\star 1}$, Brandow Lee Neri ${ }^{1}$, Diogo Farrapo Albuquerque ${ }^{1}$, Darlan Portela Fontenele' and Lucas Vieira Barros ${ }^{1},{ }^{1}$ University of Brasilia

Copyright 2021, SBGf - Sociedade Brasileira de Geofísica

This paper was prepared for presentation during the $17^{\text {th }}$ International Congress of the Brazilian Geophysical Society held in Rio de Janeiro, Brazil, 16-19 August 2021.

Contents of this paper were reviewed by the Technical Committee of the $17^{\text {th }}$ International Congress of the Brazilian Geophysical Society and do not necessarily represent any position of the SBGf, its officers or members. Electronic reproduction or represent any position of the SBGf, its officers or members. Electronic reproduction or
storage of any part of this paper for commercial purposes without the written consent storage of any part of this paper for commercial
of the Brazilian Geophysical Society is prohibited.

\section{Abstract}

This work carried out the analysis of the infrasonic signals generated by an accidental explosion in a fireworks factory located in Turkey. For the analysis, two infrasound stations were used, the I26DE station in Germany and the I48TN station in Tunisia. From the data processing it was possible to extract important information that made it possible to locate the event using only the two stations.

\section{Introduction}

Fireworks are undoubtedly a great attraction in festive events and celebrations, such as World Cups, June parties or the great fireworks display on New Year's Eve, illuminating the skies around the world, bringing hope for a better year. However, behind the beauty and joy, they hide a sad reality: the fear faced by pyrotechnic industry workers because of the danger related mainly to their manufacture and storage.

Unfortunately, accidents in fireworks factories are not rare events to happen and another episode occurred. On the morning of a Friday, July 3, 2020, at 11:15 am (local time), 8:17 am (GMT), an accidental explosion occurred at a fireworks factory in Sakarya province in northwestern Turkey. At the time of the explosion, there were about 150 to 200 people at the scene, according to local sources. Unfortunately, the explosion resulted in at least 6 deaths and more than 100 injuries, and the cause of the accident is still being investigated.

It is in this context that the present work enters with the objective of analyzing the infrasonic signals generated by this explosion. The infrasound, along with 3 other geophysical sensor technologies (seismic, hydroacoustic and radionuclides) are part of the International Monitoring System (IMS) that will be used to verify compliance with the Total Nuclear Test Ban Treaty (CTBT) when it comes into force. The CTBT, although not yet in place, prohibits nuclear explosions at the global level and IMS will be used to verify compliance with the treaty, being able to detect any nuclear test with a power equal to or greater than $1 \mathrm{kt}$ of TNT.

IMS has a total of 337 installations with four technologies: 50 primary seismic stations and 120 auxiliary seismic stations; 60 infrasonic stations (Figure 1); 11 hydroacoustic stations; 80 radionuclide stations and 16 radionuclide laboratories.

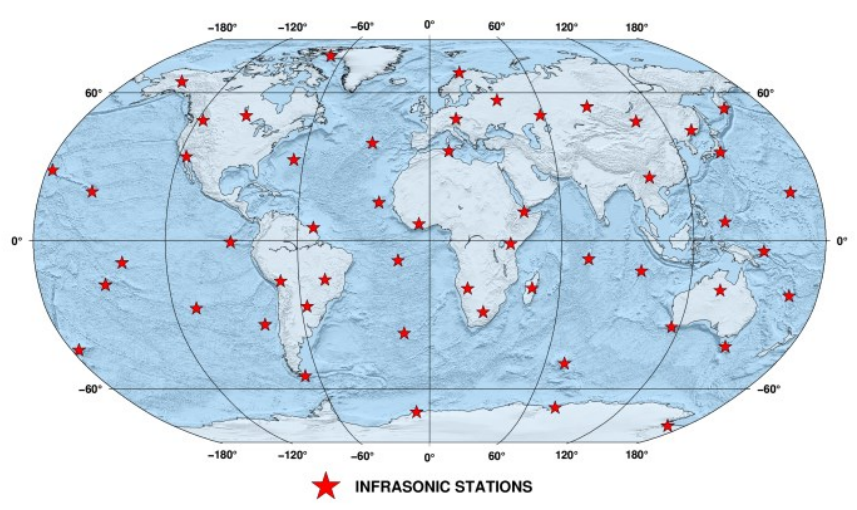

Figure 1 - IMS infrasonic stations network (60 stations).

For the analysis of the infrasonic data performed in the present study, the two stations closest to the accident site will be used: the I26DE station located in Germany, which is approximately $1590 \mathrm{~km}$ away and the 148TN station, located in Tunisia $1918 \mathrm{~km}$ away from the accident (Figure 2).

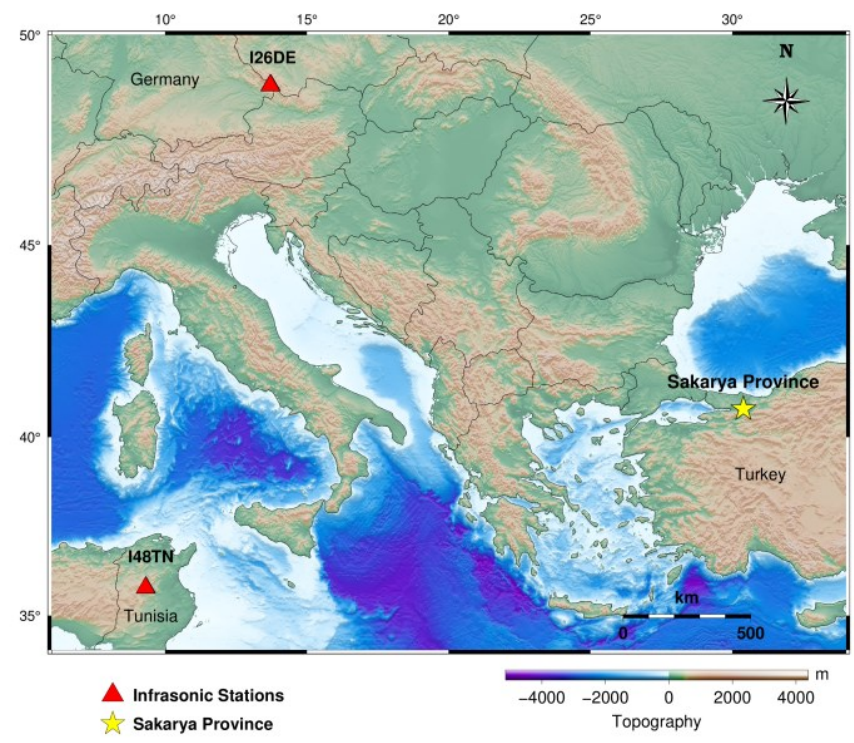

Figure 2 - Location map showing the infrasonic stations used and the location of Sakarya province. 


\section{Method}

Sound waves are longitudinal waves in which the direction of propagation is parallel to the movement of particles, traveling through a gas through compression and rarefaction. In the atmosphere, sound waves with frequencies between $20-20,000 \mathrm{~Hz}$ are audible to humans. A sound wave with a frequency higher than $20,000 \mathrm{~Hz}$ is called ultrasound. At the other end of the spectrum, sound waves with frequencies below $20 \mathrm{~Hz}$ become inaudible to humans and are called infrasound (Le Pichon et al., 2010).

The generation of an infrasonic signal can occur in various ways, such as nuclear explosions, bolides, earthquakes, accidental explosions of large proportions, volcanic eruptions, supersonic planes, storms, rocket launches, etc.

An infrasonic wave travels through the Earth's atmosphere with a speed of $343 \mathrm{~m} / \mathrm{s}$ to $20^{\circ} \mathrm{C}$. The propagation of an infrasonic wave depends on the composition, temperature and speed of the winds of the atmosphere.

Overall, the propagation speed increases with temperature and downwind. As infrasonic waves have large wavelengths, between $17 \mathrm{~m}$ and $30 \mathrm{~km}$, they travel great distances in the atmosphere, suffering low attenuation (Gossard and Hook, 1975).

An infrasonic station is made up of an array of microbarographs that are spatially distributed around a sensor installed in the center. Usually, the installation of the elements of a station is done by positioning them on the vertices of an equilateral triangle, but there are other geometries that can be adopted, depending on the conditions of the terrain and local noise of the region.

In the present work, the infrasonic data generated by the explosion of the fireworks factory in Turkey will be processed using the Multichannel Progressive Correlation (PMCC) technique (Cansi, 1995; Cansi and Klinger, 1997). This technique, originally developed for the application in seismic data, also proved to be efficient in detecting low amplitude infrasonic signals contaminated with noise.

The processing using the PMCC technique is done by grouping 3 elements of the array, being carried out consecutively in 11 frequency bands between 0.07 and $4.0 \mathrm{~Hz}$, and in windows of adjacent times in order to cover the entire period of the data under analysis (Figure 3 ).

This first stage of processing produces elementary detections that are called the PMCC pixel, which satisfy the criteria of correlation and consistency. After this, individual pixels are grouped with similar signal attributes in time, frequency, backazimuth, and horizontal velocity. Neighboring pixel groups make up a PMCC family (Figure 4).

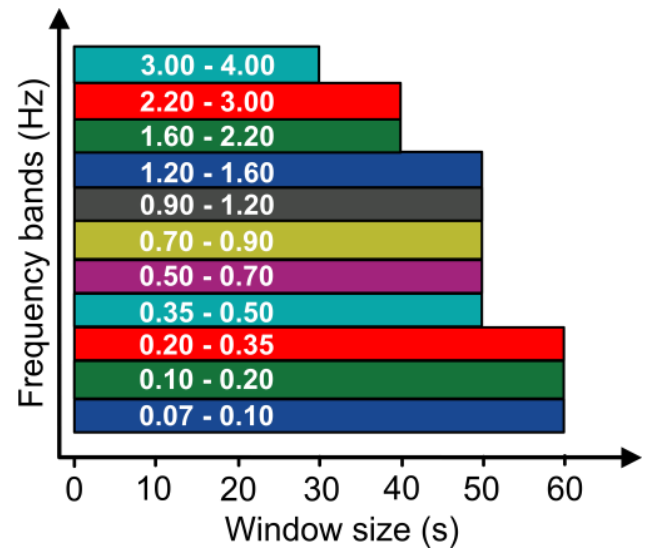

Figure 3 - Example of a PMCC configuration of 11 frequency bands (modified by Le Pichon et al, 2010).

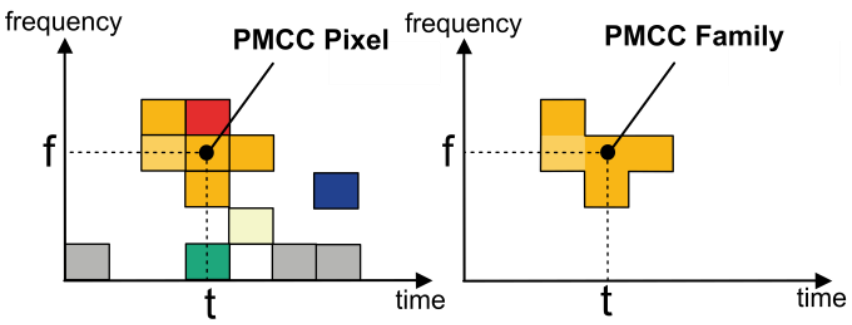

Figure 4 - Example of a PMCC family formed by pixels with similar characteristics (Le Pichon et al., 2010).

For the application of the PMCC technique, a graphical interface called GPMCC is used. This software runs the algorithm, retrieves the results, and provides some tools for further analysis.

For categorization, the algorithm examines signal detections and sorts them into phase or noise. Phased signals are associated with signals generated by events of anthropogenic or artificial origin. The categorization was developed to minimize the false associations caused by noise. Thus, some criteria were implemented in the processing according to Brachet et al. (2006):

- Maximum distance to associate arrivals of infrasonic signals is limited to $60^{\circ}$ of the source;

- $\quad$ PMCC family of at least 20 pixels (lasting over $120 \mathrm{~s})$.

For the processing and analysis of the data, it is first requested and downloaded the data from the International Data Center (IDC), located in Vienna. Then, the data is inserted into the GPMCC software, enabling interactive processing. 


\section{Infrasonic stations}

For the analysis of the infrasonic signals generated by the explosion of the fireworks factory, the two infrasonic stations closest to the accident site were used, the I26DE station (1590 km away) and the I48TN station (1918 km away).

The I26DE station installed in the Bavarian Forest, southeastern Germany, has a total of 8 elements and has been operating continuously since 1999. The I48TN station is installed in Kesra, approximately $150 \mathrm{~km}$ southwest of Tunis, northern Tunisia, has a total 7 elements and has operated continuously since 2006 (Figure 5).

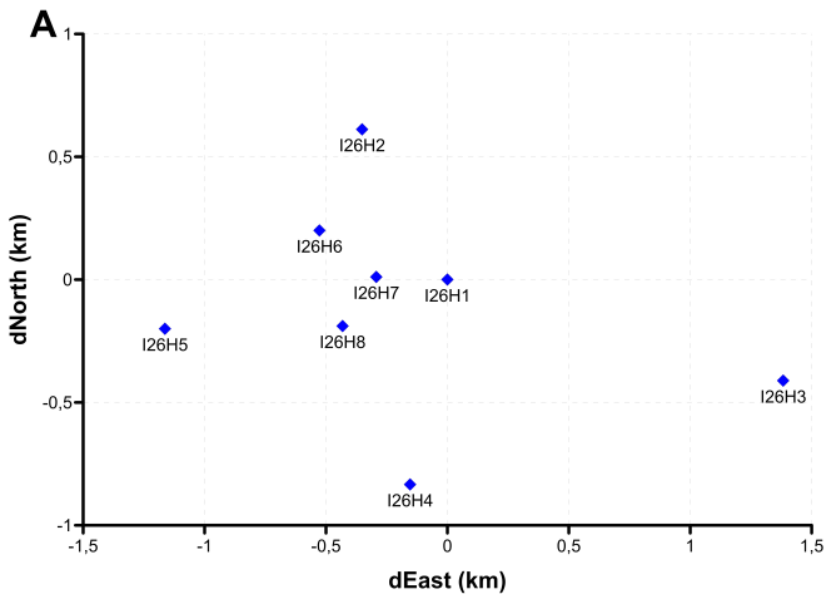

\section{Database}

The first step of process is to download the data from the IDC. The explosion occurred at 8:17 GMT and due to the distance from the stations, $1590 \mathrm{~km}$ and $1918 \mathrm{~km}$ to the I26DE and 148TN stations, respectively, the data were collected with a longer time interval to ensure that the station has detected the event. The total record obtained is 4 hours long, starting at 07:00 GMT and ending at 11:00 GMT.

Because an infrasonic station is composed of elements, each of the elements will have an associated waveform, as shown in Figure 6.

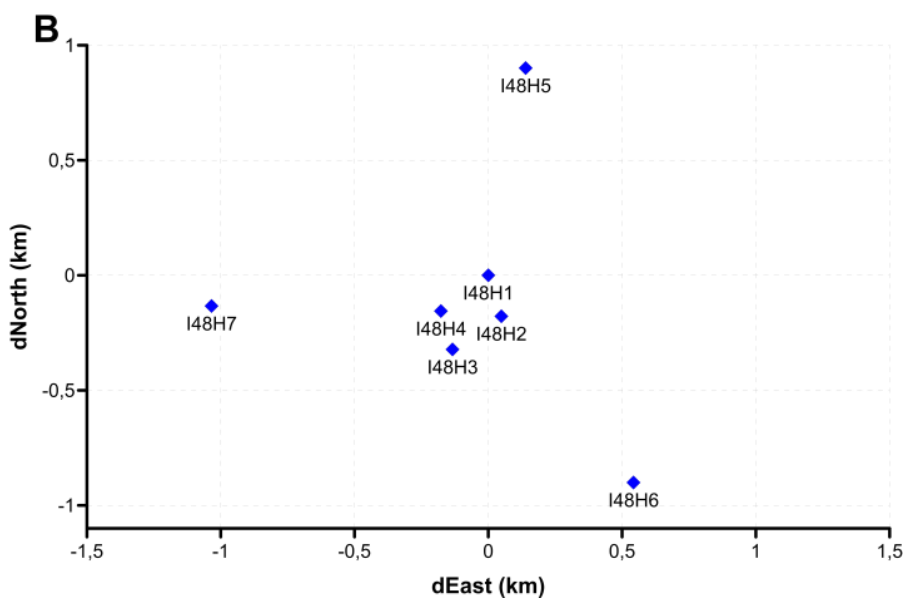

Figure 5 - Spatial distribution of station elements I26DE and I48TN in image A and B, respectively.

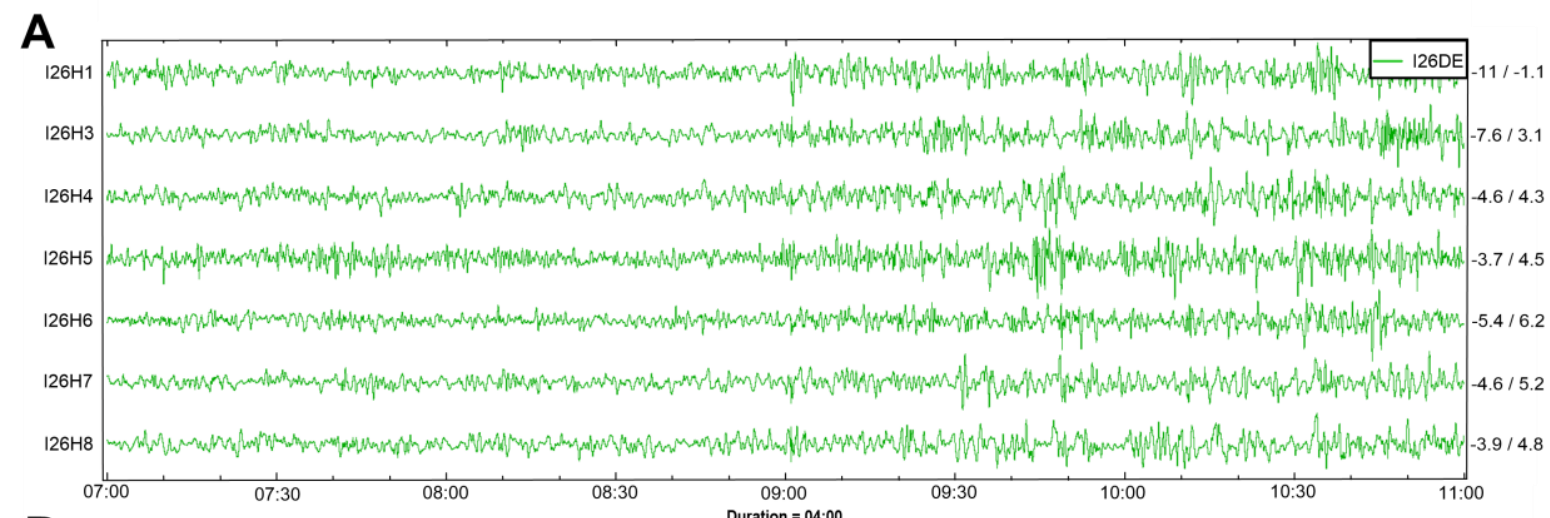

B

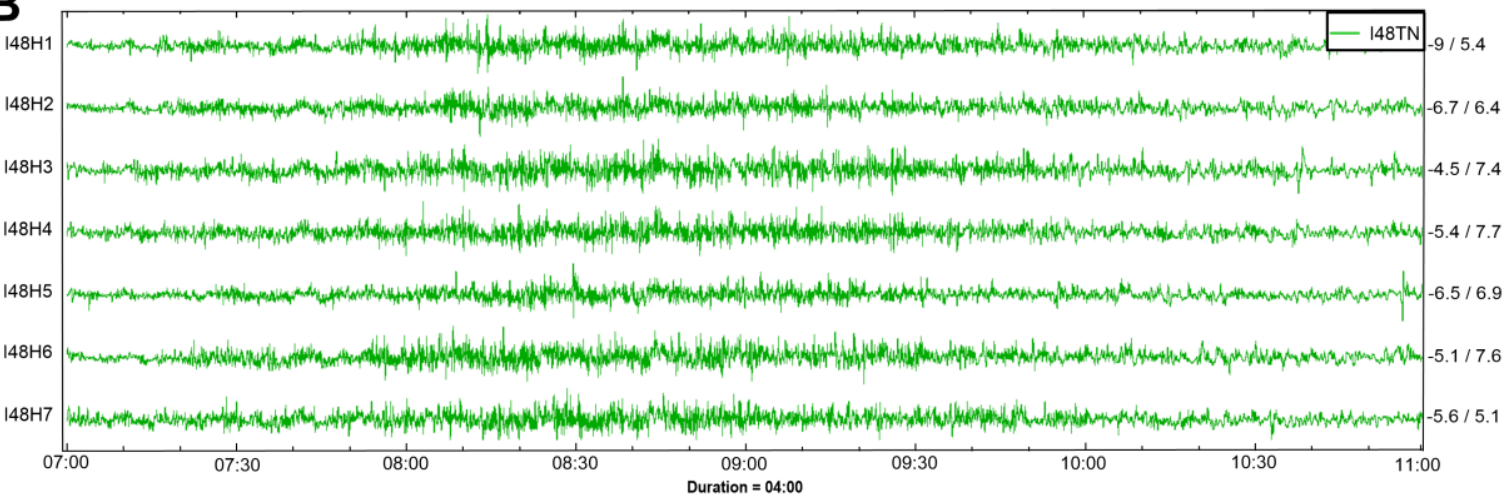

Figure 6-In A, waveforms from station I26DE and B, waveforms from the I48TN station. The H2 element of the I26DE station did not record the event. 


\section{Results}

The data is inserted within the GPMCC program and then the PMCC algorithm is run to detect the families. For this it is necessary to configure the pixels, where the distribution of frequency bands will be chosen. For the processing of this database, we used the 1/3 Octave configuration, which is already inserted and configured within the GPMCC software.

After running the PMCC algorithm, the event is located in the database so that it is possible to extract parameters such as arrival time, frequency, azimuth and speed, which will allow the location of the event using the two stations.

Figure 7 below shows the record of infrasonic signals recorded by stations I26DE and I48TN.

For the I26DE station, the arrival of the infrasonic signal was expected at about 09:33 GMT. The arrival at this station was observed at about 09:35 GMT. For the I48TN station, the arrival of the infrasonic signal was expected at about 09:50 GMT and was observed at about 09:55GMT.

As can be seen in Figure 7, infrasonic signals generated by explosions are usually composed of a series of impulsive arrivals that correspond to waves reflecting at different altitudes of the atmosphere (Le Pichon et al, 2010).

Because it is an explosion of a fireworks factory, in addition to the main explosion, other small explosions occur caused by the burning of fires that can also generate infrasonic signals that are detected in the stations. As observed at the bottom of the figure, the larger amplitude event is preceded by some smaller amplitude arrivals, and these may be correlated with small explosions.

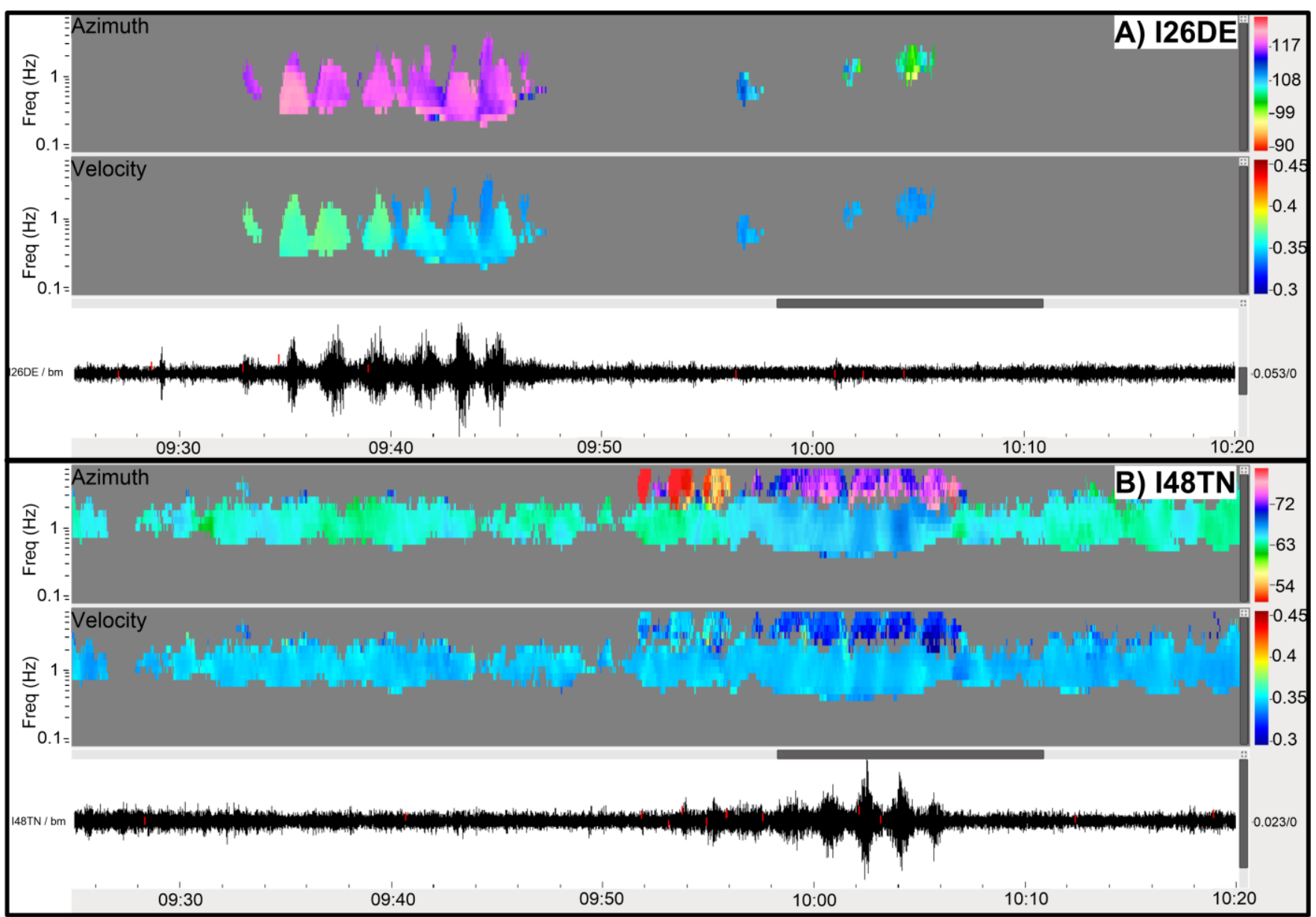

Figure 7 - Infrasonic records of the explosion of the fireworks factory in Sakarya Province, Turkey at the I26DE stations in A and I48TN in B. At the top of each figure is the azimuth of the wave front, at the center the speed and at the bottom the beamform of the waveforms recorded in each element. 
Performing the polar graph with the azimuth of the detected families, it is possible to visualize from which direction the waves are being recorded and then use this information to locate the event with the infrasonic stations (Figure 8).

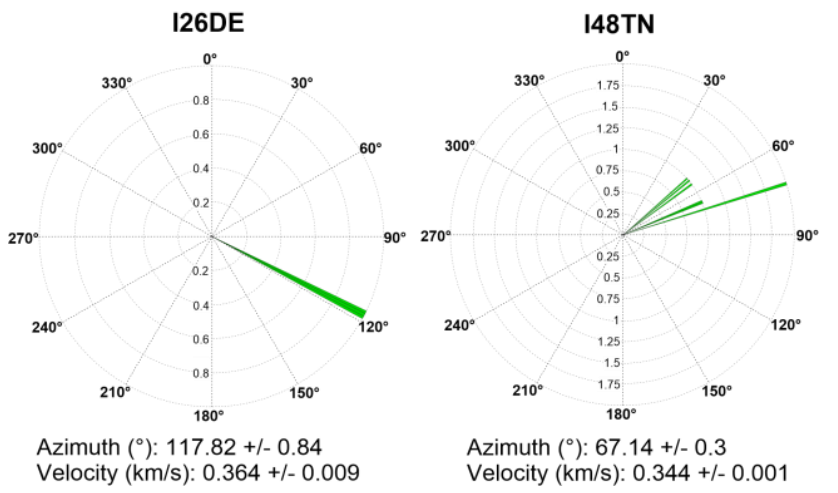

Figure 8 - Polar graph showing the azimuth of wave front arrivals at the I26DE stations on the left and I48TN on the right.

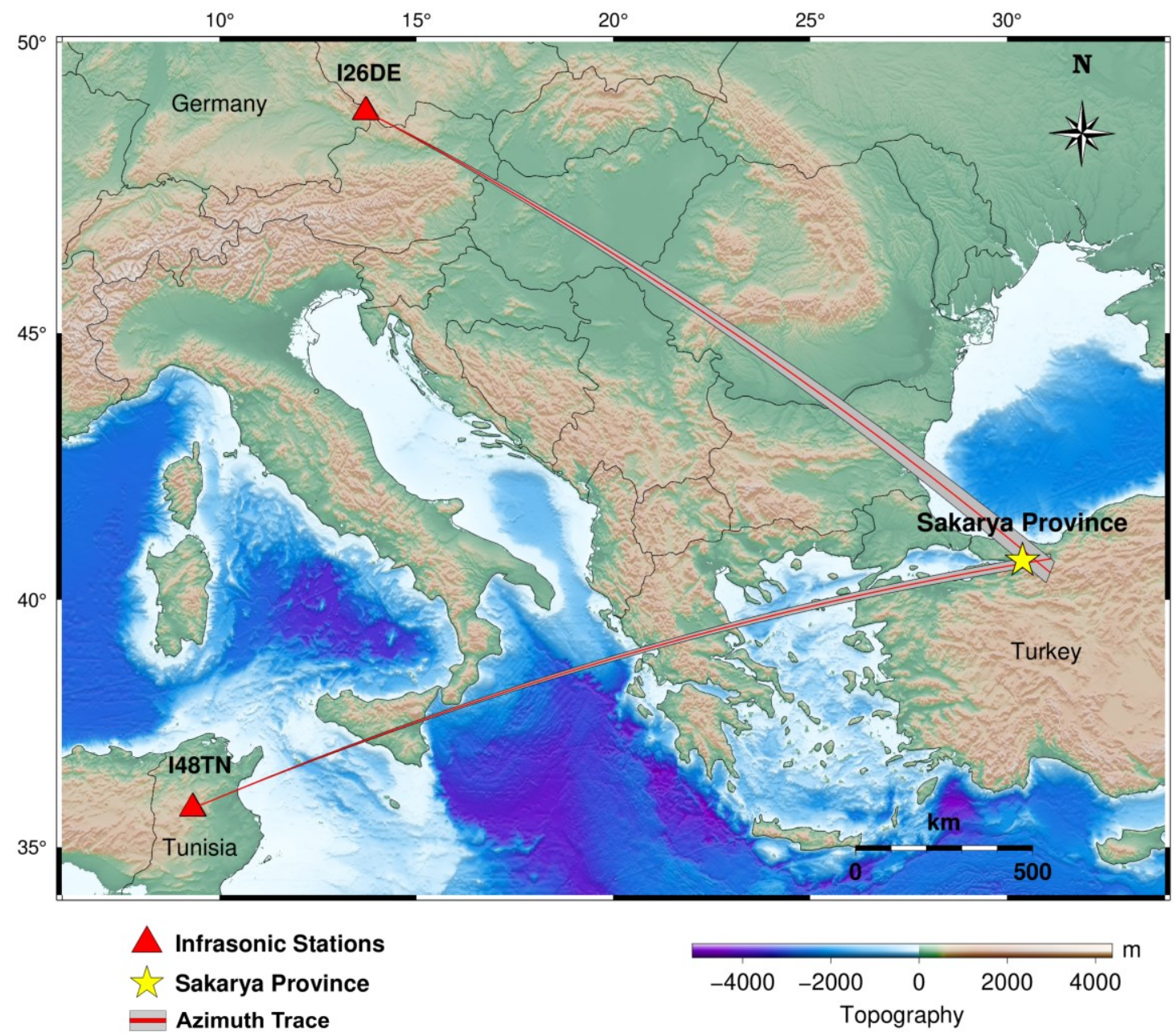

Figure 9 - Location of the explosion at a fireworks factory in Turkey. The red triangles indicate the location of the infrasonic stations and the yellow star indicates the location of the source. The rays of the azimuths of the I26DE stations, located in Germany and I48TN located in Tunisia point to the source.
From Figure 8 it is observed that for the I26DE station, the main azimuth of the wave front arrivals is $117,82+/$ 0,84 and for the 148TN station is $67,14+/-0,3$. By placing this information on a map, it is possible identify the location of the event from the ray trace at each station (Figure 9).

The map in Figure 9 shows the location of the explosion at the fireworks factory in Turkey, made from the analysis of the main azimuth of wave arrivals. The red ray is the main azimuth, and the gray bar represents the error. The azimuth rays of the I26DE and I48TN stations point to the direction of the explosion. The location made from the analysis of the infrasonic signals is presented in a precise way, considering the distance and the number of stations used.

The infrasonic signals generated by the explosion can be recorded at great distances from the station because the wave is little attenuated and its propagation is facilitated by the speed and direction of the winds. 


\section{Conclusions}

This work analyzes the infrasonic signals generated by an accidental explosion at a fireworks factory located in Sakarya province, northwestern Turkey, which occurred on July 3, 2020, at 11:15 am (local time), 8:17 am (GMT). The two infrasonic stations closest to the event were used, the I26DE station located in Germany $1590 \mathrm{~km}$ away and the I48TN station located in Tunisia, $1918 \mathrm{~km}$ away from the event.

The processing of data using the PMCC algorithm allowed the extraction of important parameters such as frequency, speed and azimuth of the wavefront, allowing the location of the explosion with data from only two stations.

The location was accurate in view of the distance from the stations. For the I26DE station the main azimuth of the wave arrivals was $117,82+/-0,84$ and for the I48TN station $67,14+/-0,3$.

Therefore, it is concluded that, the infrasonic monitoring is important for the detection, classification and localization of infrasonic sources, be they natural or artificial. From the analysis of these signals, it is possible to extract information not obtained in seismograms, such as, for example, information about the entry and explosions of meteors in the atmosphere, severe rains, supersonic airplanes, etc. In addition, it is possible to use infrasonic technology in conjunction with seismic technology for events that generate both infrasonic and seismic signals and improve the detection of the event. As it is a recent technology, infrasound has the potential for new applications such as, for example, modeling of atmospheric disturbances and climate changes.

\section{References}

BRACHET, N., COYNE, J., Le BRAS, R. 2006. Latest developments in the automatic and interactive processing of infrasound data at the IDC. Infrasound Technology Workshop, Fairbanks, Alaska.

CANSI, Y. 1995. An automatic seismic event processing for detection and location: The P.M.C.C. method.

CANSI, Y., KLINGER, Y. 1997. An automated data processing method for mini-arrays, CSEM/EMSC European-Mediterranean Seismological Centre.

GOSSARD, EE., HOOKE, WH. 1975. Waves in the atmosphere. Elsevier Amsterdam.

LE PICHON, A., CANSI, Y. 2003. PMCC for infrasound data processing. 